\title{
BETA-TRICALCIUM PHOSPHATE AND CONCENTRATED GROWTH FACTORS IN TREATMENT OF INTRA-BONY DEFECT RANDOMIZED CLINICAL TRIAL (RCT)
}

\author{
Shoukheba Malak Y.*, ELkholy Soheir E.** and Gamal Sherouk M.**
}

\begin{abstract}
This study designed to assess the efficacy of biodegradable gelatin / Beta-tricalcium phosphate sponge socked in concentrated growth factors (CGF) in treating periodontal intra-bony defects, as compared with biodegradable gelatin /beta-tricalcium phosphate sponges alone.

Materials and Methods: Twenty intra-bony defects $\geq 4 \mathrm{~mm}$ and pocket depth (PD) $\geq 5 \mathrm{~mm}$ in 20 patients were selected from the outpatient clinic of Oral Periodontology Clinic, Faculty of Dentistry, Tanta University to join in this study. Patients were randomly allocated into two groups 10 patients each. Group I was treated by surgery plus biodegradable gelatin /beta-tricalcium phosphate sponges, (control group). Group II was treated by gelatin/beta-tricalcium phosphate sponges socked in CGF. Bleeding on probing (BOP), PD and clinical attachment level (CAL) were measured at baseline, 3 , and 6months' periods. Cone beam radiographs were taken at baseline, and 6 months after surgery evaluating area of the defect (AD) and bone density (BD).
\end{abstract}

Results: Both groups showed significant improvement in clinical parameters $(\mathrm{P}<0.05)$. There were statistically significant differences in all investigated parameters between the two groups at 3 and 6 months' in favor to group II, except for CAL there was no significant difference between them at 6 months. A significant decrease of DA and increase in BD at 6 months was noted for both groups with significant differences between them in favor of group II $(\mathrm{P}<0.05)$.

Conclusion: Using a biodegradable gelatin/ $\beta$-TCP socked in CGF could enhance the outcome of periodontal regeneration, as evidenced by improved bone density and reduction in the defect area.

KEY WARDS: Beta-Tricalcium phosphate, Periodontal regeneration, Concentrated growth factors, Intra-bony defect, Cone beam-computerized tomography.

\footnotetext{
* Associate Prof of Oral Medicine, Periodontology, Oral Diagnosis and Oral Radiology, Faculty of Dentistry, Tanta University.

** Lecture of Oral Medicine, Periodontology, Oral Diagnosis and Oral Radiology, Faculty of Dentistry, Tanta University.
} 


\section{INTRODUCTION}

The innovative therapy by platelet-rich plasma (PRP), platelet-derived growth factors (PDGFs), bone morphogenic proteins (BMP), and other growth factors has given a new promise for better outcomes in periodontal regeneration. ${ }^{[1]}$

A convenient method to obtain a high concentration of PDGFs is by preparing autologous plateletrich protein (PRP), which is considered the first generation of platelet concentrate. ${ }^{[2]}$ The second generation of platelet concentrate, is platelet-rich fibrin (PRF), which is neither fibrin glue nor standard platelet concentrate, it was developed in 2001 by Choukroun et al., ${ }^{[3]}$ for particular use in periodontal and maxillofacial surgery. ${ }^{[4]}$ This marvelous structure acts as a scaffold and vehicle for carrying cells, cell migration and proliferation, which are important for various tissue regeneration. ${ }^{[5]}$

The concentrated growth factors (CGF) being considered a new generation of fibrin matrix blocks was evidenced to contain a high growth factors concentration, including platelet-derived growth factor (PDGF), insulin-like growth factor (IGF), fibroblast growth factor (FGF), transforming growth factor-b (TGF-b), epidermal growth factor (EGF), and bone morphogenic protein (BMP). ${ }^{[6,7]}$

CGF is better than platelet-rich plasma (PRP) in the ease of preparation and application, minimal cost, and lack of biochemical modification (no bovine thrombin or anticoagulant is used). It can also function as a resorbable interpositional membrane, which is not present in PRP preparations. ${ }^{[8]}$

Many scaffolds have been used as growth factor carriers in an attempt to improve bioavailability at therapeutic sites to control the release and to attain stable long-term effects. ${ }^{[9]}$ The gelatin scaffolds as a carrier offer controlled release of rh bone morphogenetic protein- 2 (rhBMP-2) and rhFGF-2, ${ }^{[10]}$ and are thus efficient in promoting new bone formation in different experimental bone defects. ${ }^{[1-13]}$

The gelatin sponge not only offers a three-dimensional (3D) structure for bone progenitors but also works as a carrier for growth factors. The high solubility and controllable bioresorption rate of BTCP make it suitable as a drug delivery system. ${ }^{[14]}$

The use of $\beta$-TCP improves the mechanical properties of gelatin scaffolds without altering the porous structure and promotes the attachment, proliferation, and osteogenic differentiation of mesenchymal cells. ${ }^{[15]}$

Until now the evidence on the use of CGF are restricted, ${ }^{[16]}$ it includes chiefly nonrandomized studies, basic sciences, animal and experimental studies. Hence, this study was conducted to appraise the regenerative effect of concentrated growth factors carried on biodegradable gelatin/betatricalcium phosphate sponges in the treatment of intrabony defects.

\section{MATERIAL AND METHODS}

The study was completed by 20 patients ( 20 sites with intra-bony defects), (12 females and 8 males) who could attend the follow-up, their age ranged from 30 to 50 years suffering from moderate to severe chronic periodontitis (Stage II/III Grade A-B) were recruited from the outpatient clinic of Periodontology Clinic Faculty of Dentistry, Tanta University to participate in this study. All patients were informed about the nature of this study and signed a written informed consent prior to their inclusion. Ethical approval was taken from the ethic committee of the Faculty of Dentistry, Tanta University and ClinicalTrials.gov Identifier: NCT04698317.

Subject Inclusion: was based on the presence of one tooth at least with PPD and CAL loss of greater than or equal to $5 \mathrm{~mm}$ and radiographic evidence of intrabony defect of greater than or equal to $4 \mathrm{~mm}$, systemically healthy patients and only patients with optimal compliance and should demonstrate their ability to maintain good oral hygiene were selected. Patients who had not received any medications for the previous six months that may interfere with periodontal tissue health or healing were also included in the study. 


\section{Exclusion Criteria}

Smokers and pregnant patients. Medically compromised patients and systemic conditions precluding periodontal surgery. Subjects who do not comply with oral hygiene measures as evidenced in recall visits. Patient with restoration or caries in the site to be treated or non-vital tooth was excluded from the study.

\section{Power Analysis}

The sample size and power analysis was calculated using Epi-Info software statistical package created by the World Health organization and center for Disease Control and Prevention, Atlanta, Georgia, USA version 2002.

The criteria used for sample size calculation were as follows:

$-95 \%$ confidence limit

$-80 \%$ power of the study

The sample size was found at $\mathrm{N}=10$ for each study group. With a total sample size of 20 participants.

\section{Study design}

All patients underwent initial therapy, including oral hygiene instruction, full-mouth scaling and root planing and occlusal adjustment if needed. Patients who met all criteria for entry in surgical phase of the study were randomized by using sealed envelopes method into 2 groups, 10 patients each. Group I was treated with surgery plus biodegradable gelatin $/ \beta$ TCP alone (control group). Group II was treated with the same surgical technique plus biodegradable gelatin sponge loaded with $\beta$-TCP socked in the CGF (test group). Investigator M S screened the patients and randomly assigned them to the test and control groups and performed the surgical procedure for all the study participants. Investigator $\mathrm{S} \mathrm{G}$ and $\mathrm{S} \mathrm{kh}$ were masked to the randomization for the extent of the study and they recorded the clinical soft tissue and radiographic parameters at various time periods of the study.

Clinical parameters were taken at baseline, 3 and 6 months' evaluation periods which include probing pocket depth (PPD), ${ }^{[17]}$ clinical attachment level $(\mathrm{CAL})^{[17]}$ and bleeding on probing (BOP). ${ }^{[18]}$

Occlusal stent was fabricated to be used for standardization as a fixed reference point and fixed angulation for accurate positioning of the probes along the study evaluation periods (fig. 1).

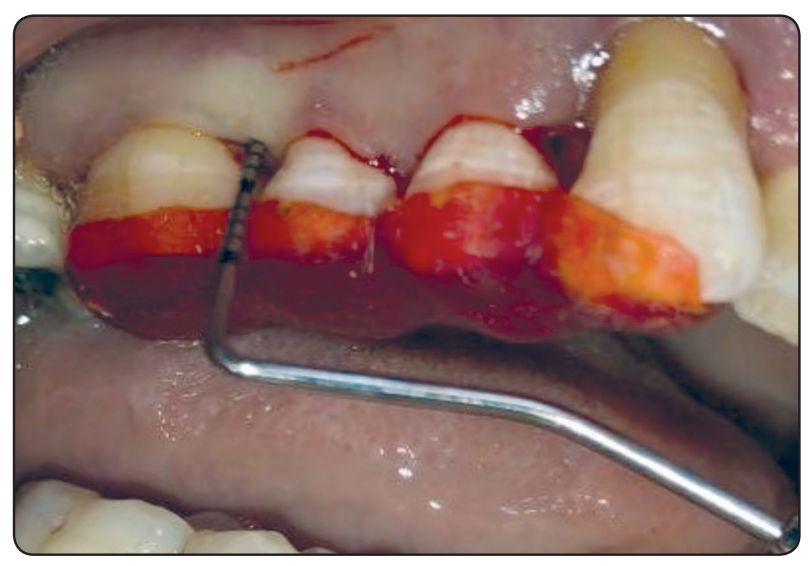

Fig. (1) Preoperative measurements using an occlusal stent.

Cone beam computed tomography (CBCT) was taken at baseline and after 6 months to measure the area of the defect (AD) and bone density using Hounsfield unit (HU).

\section{Material preparation}

Gelatin sponge loaded with beta tricalcium phosphate was prepared at Nonotech Company Cairo Egypt According to Shujaa Addin, ${ }^{[19]}$ gelatin sponges containing 50\% $\beta$-TCP (average diameter, $2.89 \mu \mathrm{m})$ were exposed to chemical cross-linking with glutaraldehyde. Briefly, an aqueous solution of gelatin was mixed with $50 \% \beta$-TCP granules at $5000 \mathrm{rpm}$ and $37^{\circ} \mathrm{C}$ by a homogenized. This was followed by adding $0.16 \%$ glutaraldehyde, which was further mixed for 15 seconds with the homogenizer. The resulting mixture was cast into a polypropylene dish and incubated at $4{ }^{\circ} \mathrm{C}$ for $12 \mathrm{~h}$ to 
permit gelatin crosslinking. The residual aldehyde groups of glutaraldehyde were blocked by placing the cross-linked gelatin/ $\beta$-TCP sponges.in 100 $\mathrm{mmol} / \mathrm{L}$ aqueous glycine solution at $37^{\circ} \mathrm{C}$ for $1 \mathrm{~h}$. Then the sponges were washed with distilled water, freeze-dried and cut into $15 \times 10 \times 10 \mathrm{~mm}$ cubes.

For the preparation of concentrated growth factor (liquid phase), $10 \mathrm{ml}$ of the patient's blood was withdrawn and tubes were kept for centrifugation with one-step centrifugation protocol: $30 \mathrm{sec}$ -acceleration, $2 \mathrm{~min}$ - $2700 \mathrm{rpm}, 4 \mathrm{~min} 2400 \mathrm{rpm}, 4 \mathrm{~min}$ - $2700 \mathrm{rpm}, 3 \mathrm{~min}$ - $3000 \mathrm{rpm}, 36 \mathrm{sec}$ - deceleration and stop. This results in 4 different phases. ${ }^{[20]}$

1. Superior phase-Serum,

2. Interim phase - Fibrin buffy coat

3. Liquid phase - (liquid phase contains growth

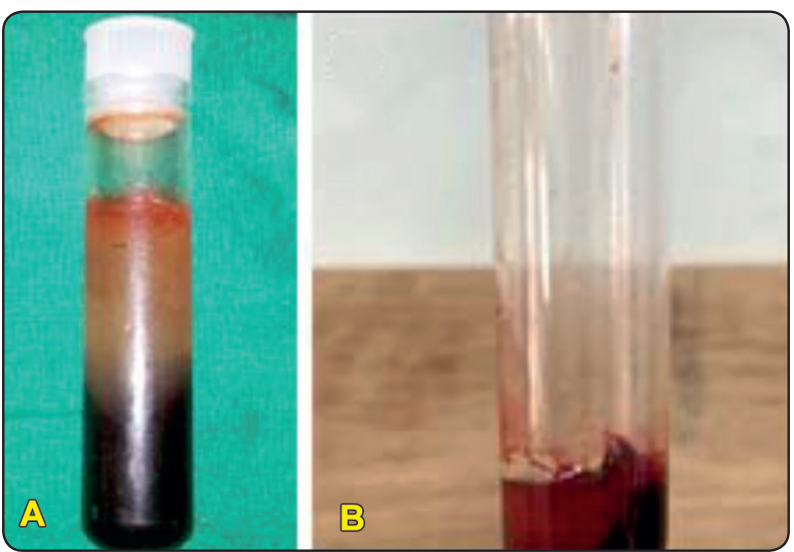

Fig. (2) Preparation of liquid phase CGF.

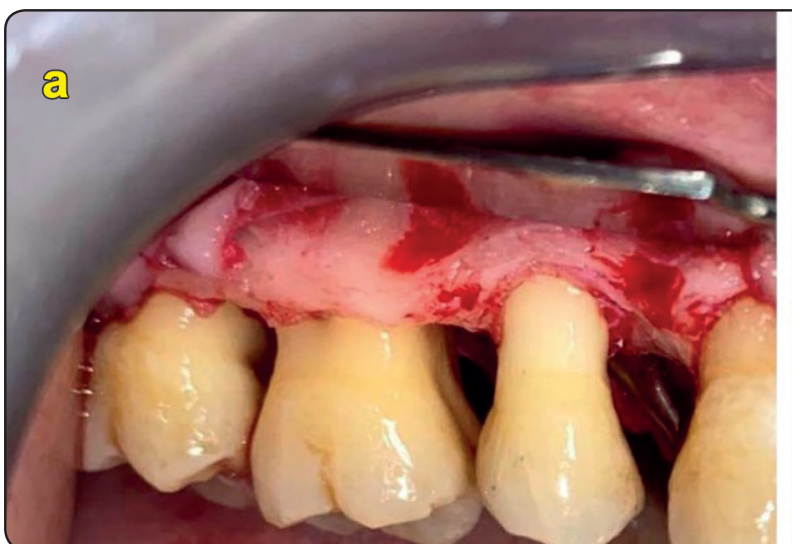

Fig. (3) Beta-tricalcium phosphate gelatin sponge socked in

CGF

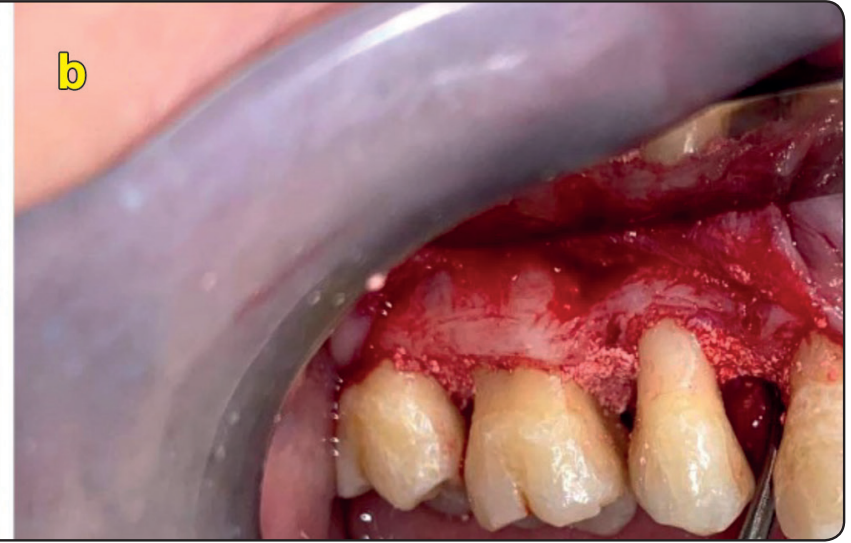

Fig. (4): a) Surgical sites after debridement and removal of granulation tissues. b) Application of Beta-tricalcium phosphate sponge socked in concentrated growth factors in the defect.

factors, leukocytes and stem cells which are capable to differentiate into their specialized cell types. (Fig. 2).

\section{Lower phase - Red blood cells}

The gelatin sponge loaded with $\beta$-TCP was soaked in the liquid phase containing growth factors before its application in the defect (Fig. 3)

The surgery was performed under local anesthesia of $2 \%$ lignocaine containing 1:100,000 of adrenaline concentration. Sulcular incision mucoperiosteal flap was reflected and complete debridement of the defect by scaling and root planing was accomplished. The defects were packed with biodegradable gelatin/ß-TCP sponges incorporating CGF [Fig 4. a\&b]. The flaps were then sutured with an interrupted suture technique using 3 zero silk

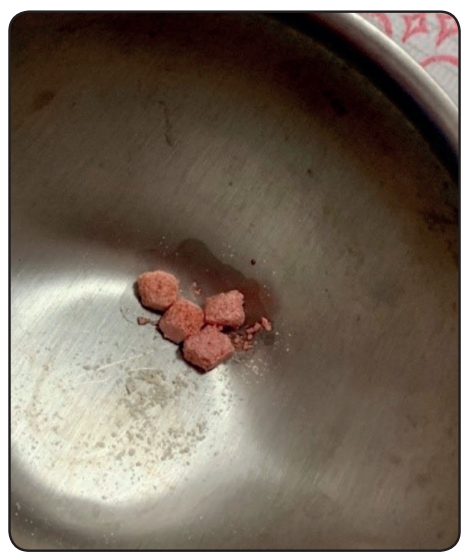


[Fig. 5]. Periodontal dressing was retained over the surgical site for 10 days. Antibiotics (Augmentin $1 \mathrm{gm}$ once per day), analgesics (Ibuprofen $400 \mathrm{mg}$ twice daily were prescribed to the patients for one week), and patients were instructed to rinse by $0.12 \%$ Chlorhexidine (CHX) three times per day for one week. Patients were recalled after 10 days for suture removal. Patients were watched on a weekly plan postoperatively, to certify good oral hygiene. At 3 and 6 months, the patients were inspected again for all clinical parameters. Similarly, the surgical procedure was carried out for the control group without CGF. All patients were treated by the same surgeon.

\section{Statistical analysis}

The data were analyzed using version 20 (SPSS). For numerical values, the range, mean and standard deviations were calculated. Intragroup comparison was done using paired t-test was used for intragroup comparison to the baseline values. The differences between groups were statistically analyzed using independent t-test

\section{RESULTS}

The patients' demographics showed no difference in groups being studied regarding age and sex. No subjects were lost or excluded over the following 6 months. The performed treatment was well tolerated by all the patients without any side effects. During the study, patient's oral hygiene level remained stable. (Table 1)

The two groups being studied showed statistically significant improvement in PPD, CAL and BOP at 3 , and 6 months' post-surgery compared with the mean baseline value $(\mathrm{P} \leq 0.05)$

The intergroup comparison demonstrated a statistically significant difference between the groups being studied for all clinical parameters at all the evaluation periods ( $\mathrm{P}>0.05)$ in favor to group II except for CAL, whereas there was no statistically significant difference between the two groups at 6 months. (table 2)

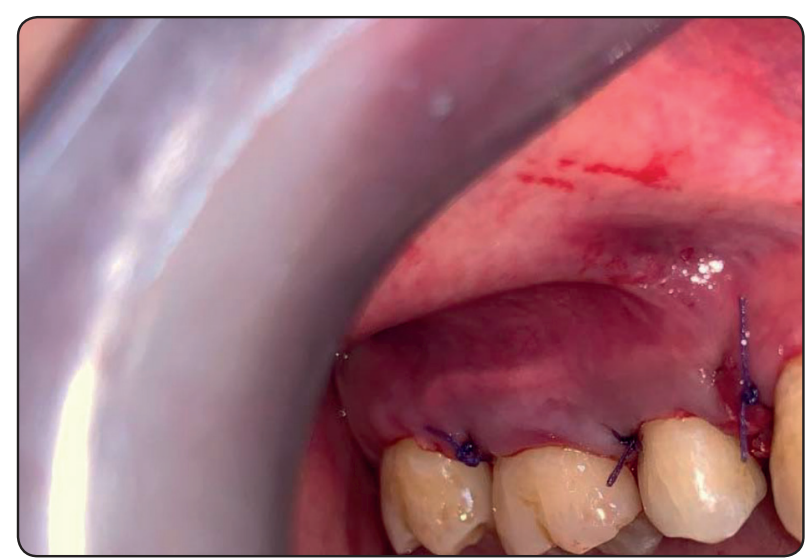

Fig. (5): Flap closure with interrupted suture.

TABLE (1): Comparison between the two study groups regarding to biographic data:

\begin{tabular}{|c|c|c|c|}
\hline & $\begin{array}{l}\text { Control group } \\
\text { (group I) } \\
\text { (B-TCP alone) } \\
(\mathbf{n}=\mathbf{1 0})\end{array}$ & $\begin{array}{c}\text { Test group } \\
\text { (Group II) } \\
\text { (B-TCP+CGF) } \\
(\mathbf{n}=\mathbf{1 0})\end{array}$ & $\begin{array}{c}\text { The test } \\
\text { of sig. }\end{array}$ \\
\hline \multicolumn{3}{|l|}{ Gender } & \\
\hline Male & $5(50 \%)$ & $3(30 \%)$ & \multirow{2}{*}{$\chi^{2}=0.833 \mathrm{~ns}$} \\
\hline Female & $5(50 \%)$ & $7(70 \%)$ & \\
\hline \multicolumn{3}{|l|}{ Age } & \\
\hline Mean \pm SD & $40.6 \pm 4.9$ & $38.8 \pm 3.7$ & $\mathrm{t}=0.926 \mathrm{~ns}$ \\
\hline
\end{tabular}

2: Chi-square test $\quad t$ : Student t-test

p: $p$ value for comparison between the two groups under study. level of significance is at $P>0.05 \quad n=$ number of patients

Radiographic evaluation results analysis, regarding to the defect area (DA) and bone density (BD) results showed a statistically significant reduction in the mean values of DA and increase in BD at 6 months as compared to their baseline values for the two groups $(\mathrm{P}<0.05)$ (table 3 , fig. 6\&7). The intergroup comparison showed a statistically significant difference between the two treated groups at 6 months' study interval $(\mathrm{P}<0.05)$ in favor of group II. 
TABLE (2): Effect of different treatment modalities on the mean of probing pocket depth (PD), clinical attachment level (CAL), and bleeding on probing (BOP) scores at the study evaluation periods.

\begin{tabular}{|c|c|c|c|c|c|}
\hline Time of assessment & \multicolumn{2}{|c|}{$\begin{array}{c}\text { Control group (group I) } \\
\text { (B-TCP alone) }(\mathbf{n}=\mathbf{1 0})\end{array}$} & \multicolumn{2}{|c|}{$\begin{array}{c}\text { Test group (Group II) } \\
(\mathrm{B}-\mathrm{TCP}+\mathrm{CGF})(\mathrm{n}=\mathbf{1 0})\end{array}$} & P0 \\
\hline $\mathrm{PPD}$ at Baseline Mean $\pm \mathrm{SD}$ & \multicolumn{2}{|c|}{$6.1 \pm 0.737$} & \multicolumn{2}{|c|}{$6.0 \pm 0.81$} & $0.777 \mathrm{~ns}$ \\
\hline PPD at 3 Months Mean \pm SD & $4.4 \pm 0.69$ & $\mathrm{P}=0.000^{* * *}$ & $3.5 \pm 0.52$ & $\mathrm{P}=0.000^{* * *}$ & $0.04^{*}$ \\
\hline PPD at 6 Months Mean \pm SD & $4.8 \pm 0.63$ & $\mathrm{P}=0.000^{* * *}$ & $3.7 \pm 0.67$ & $\mathrm{P}=0.000$ & $0.01^{*}$ \\
\hline CAL at Baseline Mean \pm SD & $5.6 \pm 0.51$ & & $5.2 \pm 0.42$ & & 0.71 \\
\hline CAL at 3 Months Mean \pm SD & $4.4 \pm 0.51$ & $\mathrm{P}=0.000^{* * *}$ & $3.8 \pm 0.42$ & $\mathrm{P}=0.000^{* * *}$ & $0.01^{*}$ \\
\hline CAL at 6 Months Mean \pm SD & $4.8 \pm 0.42$ & $\mathrm{P}=0.01^{*}$ & $4.4 \pm 0.51$ & $\mathrm{P}=0.01^{* *}$ & $0.7 \mathrm{~ns}$ \\
\hline BOP at Baseline Mean \pm SD & $78.51 \% \pm 12.48$ & & $77.5 \% \pm 18.14$ & & $0.8 \mathrm{~ns}$ \\
\hline BOP at 3 Months Mean \pm SD & $35.0 \% \pm 10.27$ & $\mathrm{P}=0.000^{* * * *}$ & $20.5 \pm 16.06$ & $\mathrm{P}=0.000^{* * * *}$ & $0.02^{*}$ \\
\hline Bop at 6 Months Mean \pm SD & $37.5 \% \pm 12.52$ & $\mathrm{P}=0.000^{* * * *}$ & $19.0 \% \pm 18.2$ & $\mathrm{P}=0.000^{* * * *}$ & $0.016^{*}$ \\
\hline
\end{tabular}

*P-value $<0.05$, statistically significant. P0: independent t test. $\quad P$ : paired student $t$ test.

B-TCP: Beta tricalcium phosphate $\quad B-T C P+C G F:$ Beta tricalcium phosphate + concentrated growth factors

$n=$ number of patients

TABLE (3): Comparison between the two groups being studied according to area of the defect (AD) and bone density (BD) at baseline and 6 months' post-surgery

\begin{tabular}{|l|c|c|c|c|c|}
\hline Time of assessment & \multicolumn{2}{|c|}{$\begin{array}{c}\text { Control group (group I) } \\
\text { (B-TCP alone) }(\mathbf{n}=\mathbf{1 0})\end{array}$} & \multicolumn{2}{c|}{$\begin{array}{c}\text { Test group (Group II) } \\
\text { (B-TCP+CGF) }(\mathbf{n}=\mathbf{1 0})\end{array}$} & P0 \\
\hline AD at Baseline Mean $\pm \mathrm{SD}$ & \multicolumn{2}{|c|}{$1.63 \pm 0.19$} & \multicolumn{2}{|c|}{$1.53 \pm 0.19$} & $0.71 \mathrm{~ns}$ \\
\hline AD at 6 Months Mean $\pm \mathrm{SD}$ & $0.75 \pm 0.26$ & $\mathrm{P}=0.000^{* * * *}$ & $0.75 \pm 0.26$ & $\mathrm{P}=0.000^{* * * *}$ & $0.001^{* * * *}$ \\
\hline BD at Baseline Mean $\pm \mathrm{SD}$ & $514.79 \pm 13.23$ & & $514.79 \pm 13.2$ & & $0.35 \mathrm{~ns}$ \\
\hline BD at 6 Months Mean $\pm \mathrm{SD}$ & $748.05 \pm 19.07$ & $\mathrm{P}=0.000^{* * * *}$ & $748.05 \pm 19.07$ & $\mathrm{P}=0.000^{* * *}$ & $0.000^{* * *}$ \\
\hline
\end{tabular}

*P-value $<0.05$, statistically significant.

B-TCP: Beta tricalcium phosphate

P0: independent t test.

P: paired student t test.

$n=$ number of patients
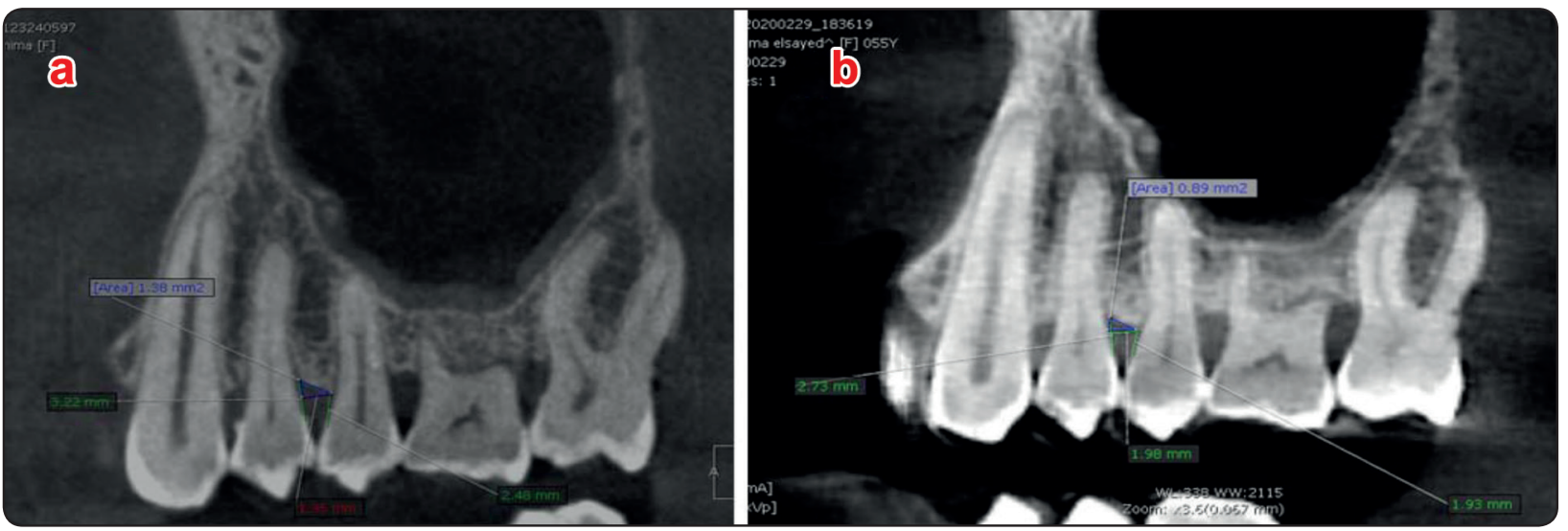

Fig. (6): CBCT at baseline and after 6 months - sagittal view - area of the defect (AD). 

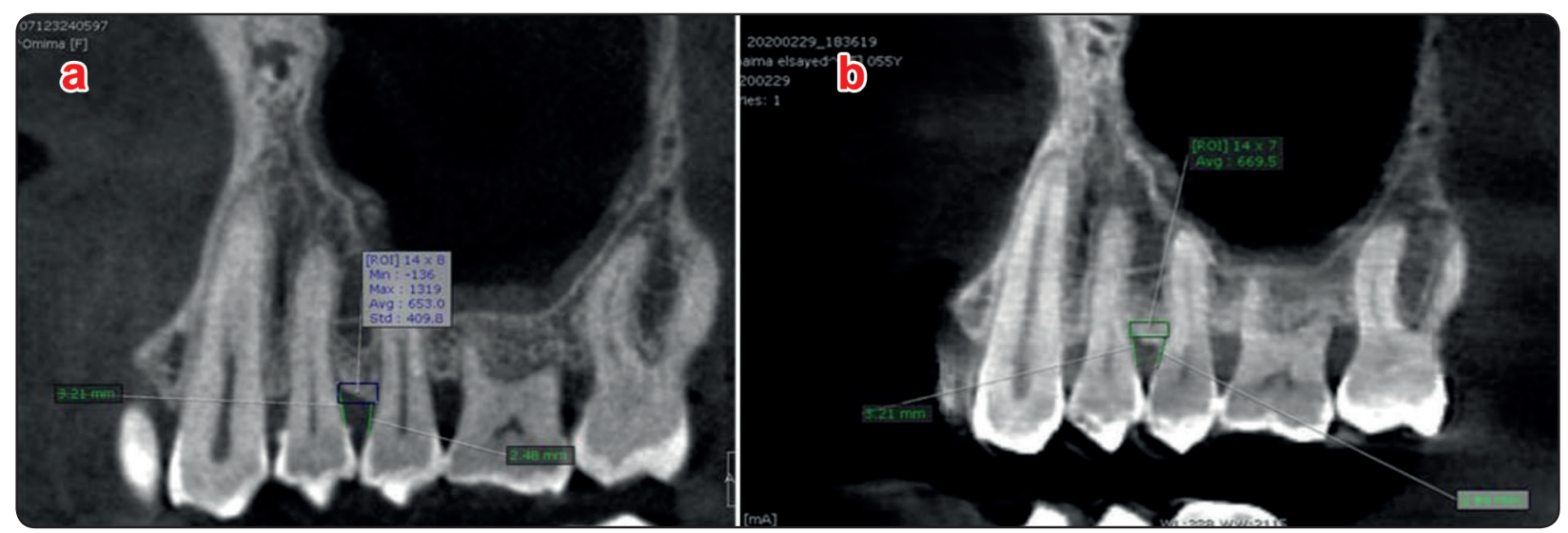

Fig. (7): CBCT at baseline and after 6 months - sagittal view - bone density (BD) by ROI.

\section{DISCUSSION}

Platelet concentrates represent a new tactic to improve periodontal regeneration, it can be used alone or with bone graft to induce tissue regeneration. Concentrated growth factors (CGFs) are advanced generation from platelet concentrates that have an exciting clinical and biotechnological application potential. ${ }^{[21]}$

CGF is characterized by a firm fibrin scaffold and the non-stop release of growth factors. ${ }^{[16]}$ Bonnazza et al., ${ }^{[22]}$ suggested that $\beta$-TCP in addition to CGF could reinforce and improve tissue regeneration, especially bone regeneration and help prolong bioactive duration of CGF, Hence the current study evaluated the biodegradable gelatin sponge loaded with $\beta$-TCP socked in CGF in treatment of intrabony defects.

Patients were medically free to avoid the possible impact of systemic diseases on the periodontal health condition and their possible effects on the tested clinical parameters. Comprehensive oral hygiene instructions followed properly by the patients, periodic maintenance program meticulous scaling for supra and sub gingival plaque and calculus to exclude any effect on the healing process.

In the current study BOP was used as an assessment measurement as, it is an important outcome measurement since the absence of BOP in recall patients has been associated with clinical stability over time. Furthermore, BOP associated with PD has shown the greatest diagnosis accuracy for future attachment level. ${ }^{[23]}$ While plaque Index (PI) and gingival index (GI) were not used in this study as baseline parameters were measured only after one month following phase I therapy so PI and GI were zero and patients were continuously check for their plaque control during the study period.

The current randomized controlled trial revealed favorable outcomes after 6 months There was high significant reduction in PPD and CAL in both studied groups at all study intervals as compared to baseline. Furthermore, comparison for PPD and BOP showed that at 3and 6 months' study intervals, there was a statistically significant difference in favor of group II. Hence, the use of CGF provides an additional effect as evidenced radiographically by improvement of bone density and decrease in the area of the defect. These results were in correspondence with Yan et al., ${ }^{[2]}$ who stated that CGF can promote wound healing and reduce the depth of periodontal intrabony defects.

The results of this study can be enlightened by the fact that the CGF preparations harbour high concentrations of many growth factors (e.g., TGF- $\beta 1$, PDGF-BB, VEGF, IL- $1 \beta$, and IL-6), ${ }^{[25]}$ thus CGF can encourage proliferation and osteoblast differentiation of bone marrow cells 
and then enhance cell proliferation in all the three different cell types (fibroblasts, endothelial cells and osteoblasts) involved in angiogenesis, tissue remodeling and regeneration. ${ }^{[26]}$

$\mathrm{Li}$ et al. recently stated that CGF not only has an osteogenic influence on human periodontal ligament cells (hPDLCs) in a normal culture but also endorses hPDLCs osteogenesis in a TNF- $\alpha$ induced inflammatory microenvironment. ${ }^{[27]}$

The present study found that there were statistically significant differences between the groups being studied for all clinical parameters at all evaluation periods except for CAL at 6 months there was no significant difference between the two groups. This may be explained by the slight recession that can take place after any surgery. Additionally, it can be explained by the patients factors of vigorous and over use of tooth brush.

This was in concomitant with an early study by Kim et al. ${ }^{[28]}$ to evaluate the efficacy of PRP, PRF and CGF on bone regeneration and found that all of them equally facilitated new bone formation in the early stage. However, this platelet concentrates were less effective on osteogenesis after 12 weeks of the treatment. It may be attributed to the bioactive duration of platelet concentrates, which cannot match the long-term process of new bone regeneration.

Radiographic evaluation by CBCT was used in the current study, which considered the noninvasive, superior technique for assessing hard tissue changes, bone gain, bone density. Comparing the two groups at 6 months' study interval, results showed that, there was statistically significant difference in terms of DA in favor of group II and also significant improvement in bone density values comparing to group II.

The results of the current study agreed with GÖkmenoğlu et al., ${ }^{[8]}$ who demonstrated that treatment of bone defects with CGF and bone mix resulted in significant defect fill as evidenced clinically and radiographically after one-month.
Additionally, Masuki et al. ${ }^{[25]}$ reported that CGF and PRF are superior than PRP in encouraging the proliferation of human periosteal cells. Masuki et al. ${ }^{[25]}$ Moreover, Park et al. ${ }^{[29]}$ stated that CGF had great regenerative ability in the early bone formation at a femur defect than PRF did.

Furthermore, results of the current study were confirmed by Ellithy et al., [30] who compared clinically and radiographically the effect of CGF and PRF both combined with $\beta$-tri calcium phosphate and hydroxyapatite bone graft $(\beta-\mathrm{TCP}+\mathrm{HA})$ in the treatment of intra-bony defects. Results showed that, both treatment modalities resulted in clinical improvement as well as radiographic evidence of bone regeneration so these materials could be used successfully in the treatment of patients suffering from moderate to severe chronic periodontitis. ${ }^{[30]}$

However, results were inconsistent with Kim et al., ${ }^{[28]}$ who concluded that the osteogenic effects of PRF and CGF were not greater than those of PRP. This discrepancy in results may be due to the difference in methodology as they used it in rabbit calvaria without bone graft.

Qiao et al., ${ }^{[31]}$ the combined effect of CGFs with bovine porous bone mineral graft in the treatment of human intrabony defect versus BPBM alone both clinically and radiographically. The CGFs + a BPBM group showed more satisfactory gains in radiographic parameters. However, the difference between the two groups was not significant. In contrast, this study showed significant difference in radiographic parameters at 6 months in group II than group I, which indicated that CGF enhances bone regeneration. This may be due to; the inherent limited ability of periapical radiography to evaluate true bone regeneration. Therefore, CBCT was used in the present study as it is more accurate and standardized method to evaluate defect bone fill.

The improvement in clinical and radiographic parameters in our study may be due to the favorable component in CGFs, which are the stem cells. Rodella et al., ${ }^{[32]}$ in an immunohistochemistry 
study, found that CGF contains a greater number of CD34-positive cells than in RBC layers, that is very important in osteogenesis

Additionally, $\beta$-TCP improves the mechanical properties of gelatin scaffolds without changing the porous structure and stimulate the attachment, proliferation, and osteogenic differentiation of mesenchymal cells as it provides 3-dimension scaffold for growth factor and help the attachment of bone progenitor cells. ${ }^{[14]}$

Finally, with in the limitation of the current study which include the small sample size and the short evaluation period we concluded that CGF can enhance wound healing and reduce the periodontal intrabony defect depth. Additionally, biodegradable gelatin/ß-TCP might be a superior scaffolding material that successfully carried the CGF in defects. But, more studies with higher sample sizes and strict experimental design are still needed to clarify the role of CGF on periodontal regeneration and long term results of one year or more are needed to build up stronger evidences to prove the role of CGF in biodegradable gelatin/ß-TCP in periodontal regeneration.

Challenges and coming outlooks are opened to deliver creative for the design and development of new biomaterials and delivery system for regenerative periodontal therapy.

\section{Conflict of interest: Nil}

\section{REFERENCES}

1. Suárez-López del Amo F, Monje A, Padial-Molina M, Tang $\mathrm{Z}$ and Wang H-L. Biologic agents for periodontal regeneration and implant site development. Biomed res int. 2015;2015:1-10.

2. Andia I and Abate M. Platelet-rich plasma: underlying biology and clinical correlates. Regen Med. 2013;8:645-658.

3. Choukroun J, Adda F, Schoeffler C and Vervelle A. PRF: an opportunity in perio-implantology .Implantodontie. 2001;42:55-62.
4. Dohan D, Choukroun J, Diss A, Dohan S, Dohan A, Mouhyi J, et al. Platelet-rich fibrin (PRF): a second-generation platelet concentrate. Part I: technological concepts and evolution. Oral Surg Oral Med Oral Pathol Oral Radiol Endod. 2006; 101:37-44.

5. Khiste $\mathrm{S}$, Naik Tari R. Platelet-rich fibrin as a biofuel for tissue regeneration. Biomater. 2013; 2013:1-6.

6. Sacco L. Lecture, at International academy of implant prosthesis and osteoconnection. Lecture. 2006;12:4.

7. Bernardi S, Mummolo S, Tecco S, Continenza M and Marzo G. Histological characterization of Sacco's concentrated growth factors membrane. Int J Morphol. 2017; $35: 114-119$.

8. GÖkmenoğlu C, Yavuz M, Sadik E, ÇanakÇ Vand Kara C. Treatment of Different Types of Bone Defects with Concentrated Growth Factor: Four Case Reports. Int J Oral Dent Health. 2016; 2;1-3.

9. Yongxi L, Xianghong L and Xiaohua L. Recent advances in periodontal regeneration. A biomaterial perspective Bioactive Materials. 2020; 5:297-308.

10. Young S, Wong M, Tabata Y and Mikos A. Gelatin as a delivery vehicle for the controlled release of bioactive molecules. J Control Release. 2005;109: 256-274.

11. Yamamoto M, Hokugo A, Takahashi Y, Nakano T, Hiraoka M, and Tabata Y. Combination of BMP- 2- releasing gelatin/beta- TCP sponges with autologous bone marrow for bone regeneration of X-r ay- irradiated rabbit ulnar defects. Biomaterials. 2015; 56:18-25.

12. Hoshi S, Akizuki T and Matsuura T. Ridge augmentation using recombinant human fibroblast growth factor- 2 with biodegradable gelatin sponges incorporating beta- tricalcium phosphate: a preclinical study in dogs. J Periodontal Res. 2016; 51:77-85.

13. Fujita N, Matsushita $\mathrm{T}$ and Ishida $\mathrm{K}$. An analysis of bone regeneration at a segmental bone defect by controlled release of bone morphogenetic protein 2 from a biodegradable sponge composed of gelatin and beta-tricalcium phosphate. J Tissue Eng Regen Med. 2012; 6: 291-298.

14. Bose S, Roy M and Bandyopadhyay A. Recent advances in bone tissue engineering scaffolds. Trends in biotechnology. 2012; 30:546-554.

15. Takahashi Y, Yamamoto M and Tabata Y. Osteogenic differentiation of mesenchymal stem cells in biodegradable sponges composed of gela- tin and beta- tricalcium phosphate. Biomaterials. 2005; 26: 3587-3596. 
16. Jianguo $\mathrm{C}$ and Haiyue J. A Comprehensive Review of Concentrated Growth Factors and Their Novel Applications in Facial Reconstructive and Regenerative Medicine. Aesth Plast Surg. 2020;44:1047-1057.

17. Ramjford S. The periodontal disease index (pdi). Journal of periodontology. 1967;38:602-610.

18. Ainamo J and Bay I. Problems and proposals for recording gingivitis and plaque. Int Dent J. 1975;25:229-235.

19. Shujaa Addin A, Akizuki T, Hoshi S, Matsuura T, Ikawa T, Fukuba S, et al. Biodegradable gelatin/beta-tricalcium phosphate sponges incorporating recombinant human fibroblast growth factor-2 for treatment of recession-type defects: A split-mouth study in dogs. J Periodont Res. 2017;52:863-871.

20. Kshirsagar JT, Rubine S: Innovation in regeneration Concentrated growth factor. Int. J Appl. Dent. Scien 2017; 3: 206-208.

21. Bonazza V, Hajistilly C, Patel D, Patel J, Woo R, Cocchi M, et al. Growth Factors Release From Concentrated Growth Factors: Effect of $\beta$-Tricalcium Phosphate Addition. J Craniofac Surg: 2018; 29:2291-2295.

22. Bonazza V, Borsani E, Buffoli B, Nocini P, Albanese M, Zotti F, et al. Beneficial effects of concentrated growth factors and resveratrol on human osteoblasts in vitro treated with bisphosphonates. Biomed Res Int. 2018; 16:1-13.

23. Lang NP, Adler R, Joss A, Nyman S. Absence of bleeding on probing An indicator of periodontal stability.J Clin Periodontol. 1990;17(10)714-721.

24. Yan X, Jiling Q, Qinfeng S, Shiguo Y, Wenxia W and Pishan Y. One-Year Results Evaluating the Effects of Concentrated Growth Factors on the Healing of Intrabony Defects Treated with or without Bone Substitute in Chronic Periodontitis. Med Sci Monit. 2019; 25:4384-4389.
25. Masuki H, Okudera T, Watanebe T, Suzuki M, Nishiyama $\mathrm{K}$, Okudera $\mathrm{H}$, et al. Growth factor and pro-inflammatory cytokine contents in platelet-rich plasma (PRP), plasma rich in growth factors (PRGF), advanced platelet-rich fibrin (A-PRF), and concentrated growth factors (CGF). Int J Implant Dent. 2016; 2:1-19.

26. Takeda Y, Katsutoshi K, Matsuzaka K and Inoue T. The effect of concentrated growth factor on rat bone marrow cells in vitro and on calvarial bone healing in vivo. Int $\mathbf{J}$ Oral Maxillofac Implants. 2015; 30:1187-1196.

27. Li X, Yang H, Zhang Z, Yan Z, Huling L, Zhang Y, and Wu B. Concentrated growth factor exudate enhances the proliferation of human periodontal ligament cells in the presence of TNF- $\alpha$ Mol Med Rep. 2019;19:943-950.

28. Kim T, Kim S, Sa'ndor G and Kim Y. Comparison of platelet-rich plasma (PRP), platelet-rich fibrin (PRF), and concentrated growth, factor (CGF) in rabbit-skull defect healing. Arch Oral Biol. 2014; 59:550-558.

29. Park H, Kim S, Oh J, You J, Kim J, Lim S, et al. Early bone formation at a femur defect using CGF and PRF grafts in adult dogs. Implant Dentistry. 2016; 25:387-393.

30. Ellithy A, El-Hessy A, El-Zefzaf E. Concentrated Growth Factors Versus Platelet Rich Fibrin in the Treatment of Intrabony Defects in Chronic Periodontitis. Int. J. of Dentistry and Oral Health, 2021;7:60-75.

31. Qiao J, Duan J, Zhang Y, Chu Y, Sun C. The effect of concentrated growth factors in the treatment of periodontal intrabony defects. Future Sci OA. 2016;2: FS136.

32. Rodella L, Favero G, Boninsegna R, Buffoli B, Labanca $\mathrm{M}$, Scarì G et al., Growth factors, CD34 positive cells, and fibrin network analysis in concentrated growth factors fraction. Microsc Res Tech. 2011; 74:772-777. 